\title{
COVID-19, SINDEMIA E VIOLÊNCIA ESTRUTURAL: PARTICIPAÇÃO SOCIAL E PROTESTO NA ATENÇÃO PRIMÁRIA AOS POVOS INDÍGENAS NO MATO GROSSO DO ŞUL, BRASIL
}

\author{
DANIEL SCOPEL ${ }^{1}$ \\ UFRGS, BRASIL \\ https://orcid.org/0000-0001-7074-5241 \\ RAQUEL DIAS-SCOPEL ${ }^{2}$ \\ FIOCRUZ/MS, BRASIL \\ https://orcid.org/0000-0002-9579-475X
}

\begin{abstract}
RESUMO: Os Povos Indígenas no Mato Grosso do Sul enfrentam a pandemia da COVID-19 vivenciando o agravamento das iniquidades em saúde com impactos negativos que ameaçam sua reprodução biossocial. O cenário é o de uma sindemia (SINGER e RYLKO-BAUER, 2021) que se caracteriza pela interação sinérgica entre a pandemia de Covid-19 com violência estrutural, racismo, degradação ambiental, intrusão e esbulho de territórios tradicionais. $O$ artigo trata de pesquisa etnográfica sobre os processos de participação social na gestão dos serviços públicos de atenção primária durante o período de enfrentamento à pandemia de COVID-19. Destacamos necessidade de diálogo interétnico como condição necessária para a eficiência na gestão dos serviços de saúde e para a garantia de direitos indígenas. A pandemia de COVID-19 deixa lições que precisam ser observadas. Uma delas é de que a urgência não deve ser a do "rápido retorno ao mundo como o conhecíamos" (SINGER e RYLKO-BAUER, 2021:21), mas, sim, a de conquistar um futuro em que problemas de saúde e injustiças sociais sejam enfrentados concomitantemente.
\end{abstract}

PALAVRAS-CHAVE: iniquidades em saúde, injustiça em comunicação, participação social, protestos, sindemia, violência estrutural, povos indígenas.

ABSTRACT: Indigenous Peoples in Mato Grosso do Sul face the COVID-19 pandemic experiencing increasing health inequities with negative impacts on their biosocial reproduction process. The scenario is that of a syndemic (SINGER and RYLKO-BAUER, 2021) that is characterized by the synergy between the COVID-19 and structural violence, racism, environmental degradation, intrusion, and the dispossession of traditional territories. The article discusses ethnographic data on social participation processes in the management of public primary care services during the period of fighting the COVID-19 pandemic. We highlight the need for interethnic dialogue as a necessary condition for efficiency in the management of health services and for the guarantee of indigenous rights. The COVID-19 pandemic teaches that the urgency should not be to "quickly return to the world as we knew it" (SINGER and RYLKOBAUER, 2021:21), but rather to conquer a future in which health problems and social injustices are resolved at the same time.

KEYWORDS: health inequities, injustice in communication, social participation, protests, syndemia, structural violence, indian people.

\footnotetext{
${ }^{1}$ Pós-doutorando em Antropologia Social - PPGAS/UFRGS, Brasil. E-mail: daniel.amazonia@gmail.com

${ }^{2}$ Pesquisadora titular da Fundação Oswaldo Cruz/MS. E-mail: raquel.scopel@gmail.com 
Espaço Ameríndio

\section{Introdução}

Os Povos Indígenas no Mato Grosso do Sul enfrentam a pandemia da COVID-19 vivenciando o agravamento das iniquidades em saúde com impactos negativos que ameaçam sua reprodução biossocial. O cenário dos povos indígenas no Mato Grosso do Sul é o de uma sindemia (SINGER e RYLKO-BAUER, 2021) que se caracteriza pela interação sinérgica entre a pandemia de Covid-19 com violência estrutural, racismo, degradação ambiental, intrusão e esbulho de territórios tradicionais.

No cenário sindêmico em que se encontram os povos indígenas no MS, registram-se altos índices de violência apresentando a maior taxa de homicídios contra indígenas do Brasil (CIMI, 2020). As condições de vida, em grande parte dos territórios ocupados, são marcadas por situações de degradação e contaminação ambiental. Muitas aldeias vivem sob o terror gerado por conflitos de terra. Há terras demarcadas com área insuficiente para manutenção de atividades de subsistência. Há também situações de deslocamento forçado e confinamento em reservas (BRAND, 2004; URQUIZA e PRADO, 2015). Há áreas de retomadas de territórios tradicionais, ainda sem qualquer regularização oficial que garanta a segurança e o pleno direito às infraestruturas sanitárias básicas. Há falta de acesso à água potável e ao saneamento básico em muitas aldeias (BRASIL, 2020; DIAS-SCOPEL et al. 2021). São recorrentes a desnutrição infantil, a obesidade, a hipertensão, as doenças respiratórias e parasitárias, mortalidade materna em taxas superiores às da população não indígena (BRASIL, 2020; RIBAS e PHILIPPI, 2003; FERREIRA et al. 2011 ; FÁVARO et al. 2007; BASTA et al., 2013, PÍCOLI, et al., 2017; COIMBRA, 2014). Esses e outros fatores interagem e implicam grave situação de vulnerabilidade social à pandemia de COVID-19.

Os povos indígenas no MS têm lutado para garantir as condições de sua reprodução biossocial. Isso inclui a luta pela ampliação e melhoria na qualidade da atenção primária à saúde promovida pelo Estado. Há, inclusive, atuação política de lideranças indígenas nas instâncias oficiais de participação social da gestão dos serviços ofertados pelo Estado. A participação indígena na gestão da saúde é garantida por lei através dos conselhos de saúde indígena fazendo parte do "controle social", conceito que é um dos pilares da Política Nacional de Atenção à Saúde dos Povos Indígenas (PNASPI) (BRASIL, 2002). No entanto, desafios ao efetivo exercício do controle social na saúde indígena (ATHIAS, 2004; TEIXEIRA, 2017; DIEHL e LANGDON, 2018) foram acentuados durante a pandemia. Em 2020, vários obstáculos à participação social indígena no planejamento e nas ações da atenção primária trouxeram prejuízos ao enfrentamento da pandemia (DIAS-SCOPEL, SCOPEL e DIHEL, 2021). Além de um direito previsto pela PNASPI, a participação social é compreendida como meio necessário para a eficiência na atenção à saúde em contextos interétnicos (MENÉNDEZ, 2009; ATHIAS e MACHADO, 2001; FOLLÉR, 2004; SCOPEL et al., 2015; LANGDON e DIEHL, 2007).

A análise do artigo concentra-se sobre etnografia dos processos de participação social na gestão dos serviços públicos de atenção primária durante as ações de enfrentamento à pandemia de COVID-19 entre os 
povos indígenas no $\mathrm{MS}^{3}$. Destacamos necessidade de diálogo interétnico como condição necessária para a eficiência na gestão dos serviços de saúde e para a garantia de direitos indígenas. A gestão ineficiente dos serviços de saúde tem agravado o cenário sindêmico entre os povos indígenas no MS.

\section{Colapsos e fracassos}

A atenção primaria aos povos indígenas no Brasil está sob a gestão nacional da Secretaria Especial de Saúde Indígena (SESAI) do Ministério da Saúde. No Mato Grosso do Sul, a gestão fica a cargo do Distrito Sanitário Especial Indígena de Mato Grosso do Sul (DSEl-MS), que é o maior do Brasil, atendendo população de 83.241 indígenas pertencentes a oito etnias: Atikum, Guató, Guarani Ñandeva, Guarani Kaiowá, Ofaié, Terena, Kadiwéu e Kinikinaw. O DSEI-MS registra atendimento aos indígenas em 78 aldeias e 30 áreas de retomadas (BRASIL, 2020/PDSI). A coordenação do DSEI-MS fica em Campo Grande, capital do estado de MS. A estrutura administrativa do DSEI-MS está organizada em 14 polos bases, que são unidades locais, onde ficam lotadas as Equipes Multidisciplinares de Saúde Indígena (EMSI). Cada polo base possui um chefe de polo que lidera as EMSI formadas por profissionais com diversas qualificações, desde médicos, enfermeiros, técnicos de enfermagem e agentes indígenas de saúde (AIS) e de saneamento (AISAN), além do pessoal de apoio. Em cada polo base deve haver um Conselho Local de Saúde Indígena necessariamente formado apenas por indígenas. Os conselheiros locais elegem representantes para atuarem no Conselho Distrital de Saúde Indígena (CONDISI). Os conselhos integram o chamado "controle social" e são órgãos colegiados permanentes que devem acompanhar, fiscalizar e propor ações de saúde.

Em abril de 2020, já se alertava sobre a possibilidade de haver uma disseminação alta da COVID-19 entre os povos indígenas no Brasil (CODEÇO, et al 2020). Cupertino et al. (2020) alertavam para a possibilidade de haver "[...] outra tragédia histórica" (p.611), com alta taxa de mortalidade por COVID-19 entre os povos indígenas no Brasil.

O primeiro caso de COVID-19 registrado pelo Distrito Sanitário Especial Indígena de Mato Grosso do Sul foi em 13 de maio de 2020 e 14 dias depois já eram 74 casos positivos (DIAS-SCOPEL et al., 2021). Segundo Simionatto et al. (2020, p.1), a taxa de mortalidade entre os indígenas que vivem no MS, 70 dias após o primeiro caso notificado, superou "mais que o dobro" as taxas registradas para o restante da população geral. Assim, no MS, a COVID-19 espalhou-se rapidamente

\footnotetext{
${ }^{3}$ Projeto Saúde, Sustentabilidade e Controle Social: politicas públicas e a experiência de participação social no Conselho Distrital de Saúde Indígena, Mato Grosso do Sul (Condisi-MS), coordenada por Raquel Dias-Scopel e financiada pelo Programa Inova Fiocruz, desde 2018. A inserção de campo dos pesquisadores ocorreu antes do início da pandemia por meio do CONDISI-MS. Durante a pandemia, a pesquisa continuou por meio de entrevistas por telefone, troca de mensagens, reuniões on line, inserção em grupos de WhatsApp. A segunda autora é conselheira distrital de saúde indígena desde 2018.
} 
entre os indígenas causando muitas mortes. Mesmo com subnotificações, os dados oficiais expressaram uma rápida evolução de casos de COVID19 entre os povos indígenas, como por exemplo, no DSEI-MS, que apresentava as maiores taxas de casos positivos e de mortalidade por COVID-19 em fevereiro de 2021 (MENDES et al., 2021).

A notícia dos primeiros casos motivou os indígenas a instalar barreiras sanitárias nos acessos aos territórios indígenas. Houve ampla mobilização política de lideranças, profissionais e conselheiros de saúde indígenas na promoção de ações de distanciamento social e de práticas de autoatenção (DIAS-SCOPEL et al., 2021). Diante do rápido aumento no número de casos de COVID-19 e da precariedade das condições de trabalho, profissionais de saúde indígena, conselheiros e lideranças organizaram-se na busca por parcerias institucionais. Ministério Público Federal (MFP), Conselho Indigenista Missionário (CIMI), Fundação Oswaldo Cruz, universidades federais e outras organizações civis foram acionadas para arrecadar doações de máscaras, equipamentos de proteção individual, testes rápidos, alimentos e caixas d'água. Em Dourados, houve articulação para improvisar um espaço adequado para abrigar e isolar pacientes indígenas com COVID-19 (DIAS-SCOPEL et al., 2021). Apesar dos esforços indígenas, observou-se o incremento no número de casos e óbitos, assim como do fluxo de informações falsas que promoviam o negacionismo nas comunidades indígenas. Contra o fluxo de desinformação, deve-se registrar a contribuição dos agentes indígenas de saúde e de saneamento ${ }^{4}$ que promoveram esclarecimentos à população local sobre práticas de autoatenção e medidas de afastamento social.

Desde os primeiros meses da pandemia, organizações indígenas acusam o governo federal de omissão no enfrentamento à pandemia. A Arguição de Descumprimento de Preceito Fundamental (ADPF) 709, movida pela Articulação dos Povos Indígenas do Brasil (APIB) em junho de 2020, tornou objetivas diversas falhas do governo federal na condução do enfrentamento à pandemia entre os povos indígenas. A decisão judicial no Supremo Tribunal Federal (STF) obrigou o governo a apresentar um plano geral que, apenas em março de 2021 , na sua quarta versão, foi parcialmente homologado, apesar de considerado "precário". A decisão judicial mencionava que a gestão federal parecia estar sob "colapso gerencial" (STF, 2021, p.6), uma vez que o plano apresentava inconsistências, contradições e falta de transparência. $O$ referido colapso gerencial, contudo, explicitou uma série de ações do governo federal na condução de uma política que promovia a desestruturação da gestão dos serviços de atenção primária à saúde indígena durante a pandemia, minando uma organização que já era precária e deficiente. Durante a pandemia, a gestão da atenção primária aos povos indígenas no MS revelou-se incompatível com a PNASPI. Gestores deflagraram uma série de conflitos que resultaram em prejuízos aos povos indígenas do MS.

Os efeitos do colapso citado tornam-se evidentes, por exemplo, na avaliação sobre as ações de vacinação. Em denúncia recente, de junho de

\footnotetext{
${ }^{4}$ Conforme artigo em elaboração.

SCOPEL, Daniel; NEVES, DIAS-SCOPEL, Raquel. Covid-19, sindemia e violência estrutural: participação social e protesto na atenção primária aos povos indígenas no Mato Grosso do Sul, Brasil. Espaço Ameríndio, Porto Alegre, v. 15, n. 2, p. 164-181, mai./ago. 2021.
} 
Espaço Ameríndio

2021, o Ministério Público Federal noticia que a "vacinação de indígenas fracassa" no MS. Apenas metade dos indígenas do estado, segundo dados da própria SESAI, havia recebido a segunda dose da vacina ${ }^{5}$.

\section{Desencontros e conflitos}

A série de desencontros e conflitos tem um primeiro evento significativo em dezembro de 2020, quando o coordenador do DSEI-MS havia se colocado em embate com lideranças indígenas e conselheiros de saúde durante visita a uma aldeia Terena. O coordenador defendeu publicamente o posicionamento contra a Convenção 169 da OIT, o que causou estranhamento e revolta entre os indígenas.

[O coordenador] disse que fomos orientados de forma errada sobre a 169 da OIT, pois a mesma não se refere a nós, por ser uma lei internacional [...] Rebati, mas disse que não aceita isso. Disse ainda que o Dsei ficou 5 anos com os indígenas e que não houve avanços, onde ele pega o Dsei como uma casa desarrumada que tá sendo difícil arrumar. Não aguentando essas ofensas o Cacique Conselheiro fez uma defesa, seguido pelo Pastor Presidente, muito indignado quando na fala do coordenador citando incapacidade dos indígenas [...] Pergunto: Onde estão os nossos representantes do Controle Social em deixar o coordenador dizer isso nas bases? Se depender de mim, continuarei defendendo sim a 169 da OIT [...] Entendemos que na sua visão [do coordenador] o índio é incapaz. (CONSELHEIRO DISTRITAL, mensagem de texto publicada no grupo de WhatsApp do CONDISI-MS)

O relato desse conselheiro denunciava uma postura autoritária que negava publicamente direitos dos povos indígenas. O embate revelou aos indígenas o embasamento preconceituoso que seria a marca dos conflitos da gestão do DSEI-MS. Revelava que o gestor tomava os indígenas como incapazes. O coordenador do DSEI-MS também foi acusado de racismo e ato violento contra o mesmo conselheiro de saúde indígena em outra ocasião, quando fora afrontado com cobranças acerca de plano emergencial para enfrentamento da COVID-19. Este segundo confronto fora presenciado por diversas pessoas, incluindo, o presidente e o vice do

\footnotetext{
${ }^{5}$ Veja denúncia do MPF - Mato Grosso do Sul em: < http://www.mpf.mp.br/ms/sala-de-imprensa/noticiasms/vacinacao-de-indigenas-fracassa-em-ms-e-atinge-metade-da-populacao-em-algumas-cidades $>$. Último acesso em: 10/07/2021. A notícia também ganhou repercussão em jornal local: https://midiamax.uol.com.br/cotidiano/2021/mpf-afirma-que-vacinacao-de-indigenas-fracassa-emms\#.YNPWIyHlt2s.twitter
} 
Espaço Ameríndio

CONDISI-MS. Estes dois passaram a ser acusados de omissão em defender o conselheiro indígena.

Em dezembro de 2020, houve outro evento polêmico para a gestão do DSEI-MS que gerou revolta. Várias demissões tomaram de surpresa lideranças e conselheiros de saúde indígenas. Pelo menos uma dessas demissões teve flagrante aparência de arbitrariedade. Tratava-se da demissão de uma enfermeira indígena que era reconhecida como pessoa comprometida com a saúde indígena. Ela teve um papel relevante no enfrentamento da pandemia por ter trabalhado na intermediação junto a várias instituições para obter doações de equipamentos de proteção individual aos profissionais de saúde ${ }^{6}$. Para demiti-la, a coordenação do DSEI-MS apoiou-se em avaliação da chefe do polo base de Dourados, que acusava a enfermeira indígena de não respeitar a hierarquia das equipes. Os indígenas acusaram a chefe do polo de Dourados de perseguir profissionais críticos à gestão do DSEI-MS.

A acusação sobre a enfermeira indígena pareceu injusta por refletir apenas a lógica hierárquica burocrática e conflitar com as expectativas locais sobre o papel de liderança que a enfermeira teria assumido no enfrentamento da COVID-19. "Né, a enfermeira, ela buscava por entidades, né, privadas, ONG, né, buscava né as parcerias [...]" (Iiderança indígena, entrevista telefônica em 01/03/2021). O caso foi denunciado ao MPF.

Etnografias sobre atenção primária em aldeias indígenas demonstram que as lideranças indígenas são reconhecidas pelas comunidades precisamente pela capacidade de mobilizar parcerias interétnicas e arrecadar recursos para suas aldeias (GARNELO, 2003; SCOPEL et al., 2015). No momento mais grave da crise sanitária, a enfermeira havia estabelecido parcerias institucionais e arrecado recursos para a comunidade indígena com relativa autonomia em relação ao DSEIMS. Isso era visto com algo positivo pela comunidade indígena.

A demissão da enfermeira indígena causou revolta, mas não foi um caso isolado de acusação de assédio moral e demissões. Vários outros indígenas, inclusive, AIS e AISAN foram demitidos no período. Isso foi duramente criticado por organizações indígenas através de notas e cartas abertas alertando para o absurdo das demissões em um contexto de falta de profissionais de saúde para atuar no enfrentamento da pandemia.

As organizações indígenas denunciaram que as ações do DSEI-MS eram feitas sem diálogo com os indígenas e repudiaram o desrespeito ao direito de os indígenas serem consultados, citando a Convenção 169 da $\mathrm{OIT}^{7}$. Conselheiros também acusavam o presidente do CONDISI-MS de dar aparência de legalidade para as demissões, assinando documentos sem consultar os demais conselheiros indígenas.

\footnotetext{
${ }^{6}$ Ver Veron e Guimarães (2020) sobre a omissão do governo federal em ofertar equipamentos de proteção individual.

${ }^{7}$ Veja, por exemplo, as notas de repúdio publicadas pela Aty Guasu e pela APIB, disponível respectivamente em: https://m.facebook.com/atyguasu/photos/rpp.603723103096226/2259038204231366/?type=3 https://apiboficial.org/2021/01/05/profissionais-da-saude-indigena-de-dourados-ms-sao-demitidosdurante-pandemia/
} 
Dentro das EMSI, a série de demissões gerou temor entre os profissionais: "É, porque nesse momento que a gente tá vivendo tudo é, a gente tá trabalhando meio com medo de tudo né." (EMSI em 01/03/2021). O ambiente de trabalho ficou tão tenso que alguns interlocutores se negaram a expor a própria opinião sobre a atuação do DSEI-MS durante a pandemia: "Ah, eu preferia nem falar porque tenho medo de represália. Eu prefiro nem comentar essa parte" (EMSI em $01 / 03 / 2021$ ).

[...] eu acho que acontece com toda a equipe né, é, e aqui Dourados, por exemplo, estão sofrendo pressão psicológica, assédio moral e aí acaba, Dourados tá, a coisa tá bem complicada. Eles tão sofrendo muita ameaça." (LIDERANÇA INDÍGENA, 01/03/2021).

$\mathrm{Na}$ avaliação de conselheiros de saúde indígena, o autoritarismo implantado na gestão trouxe prejuízo aos profissionais de saúde em geral e à atenção prestada. Segundo uma liderança indígena, as ameaças tinham intenção de ocultar os problemas operacionais e de gestão: "Porque a coordenação tá feia aqui em Dourados, tanto como o DSEl. Assim, só tá dando importância para maquiagem, sabe." (liderança indígena, 01/03/2021).

A metáfora da "maquiagem" emerge como falta de transparência e ocultamento da gestão ineficiente e evoca um sentido de propaganda de ações de governo como um fim em si mesma, para manutenção de uma imagem que reflete apenas interesses de governo. Também, Bruce Albert (2020) fala de uma "ruidosa ficção jornalística" promovida pela SESAI na produção de dados e na divulgação de ações oficiais realizadas para enfrentar a pandemia no contexto Amazônico.

\section{Aparelhamento repressivo}

Durante a pandemia, os Conselheiros Distritais de saúde indígena permaneceram atuantes em suas aldeias de origem e se articularam entre si trocando informações por meio de grupo do aplicativo de mensagens de WhatsApp. Entretanto, sem sucesso, vinham requerendo a realização de reunião ordinária para avaliar as ações do DSEI-MS e propor medidas específicas para o combate à pandemia de COVID-19 nas aldeias (DIASSCOPEL et al., 2021). Segundo regimento interno do CONDISI-MS, a convocação de reuniões ordinárias é prerrogativa do seu presidente, que estranhamente passou a argumentar a favor da não realização de reuniões ratificando argumentos da coordenação do DSEI-MS. O DSEI-MS apresentava como obstáculo à realização de reuniões do CONDISI-MS a necessidade de se adequar às medidas de afastamento evitando aglomeração de pessoas. O presidente passou a ser visto acompanhando o coordenador em viagens pelas aldeias. Vários conselheiros reclamavam 
Espaço Ameríndio

do silêncio do presidente acerca dos assuntos discutidos no grupo de WhatsApp.

O descontentamento com a atuação do presidente do CONDISI-MS tornou-se público a partir de meados de dezembro de 2020, quando o conselho local de sua aldeia de origem promoveu reunião para destituí-lo do cargo de conselheiro local. Os indígenas argumentaram que isso automaticamente o destituiria do cargo de presidente. Em 21 de dezembro, o secretário do CONDISI-MS oficiou ao coordenador do DSEIMS sobre a destituição. Em 04 de janeiro de 2021, o secretário do CONDISI solicitou ao coordenador do DSEI-MS apoio para uma reunião extraordinária com objetivo de realizar nova eleição para cargo de presidente e vice-presidente. Nesse ponto, o presidente se mostrava alinhado ao coordenador e, no dia 06 de janeiro de 2021, o presidente do CONDISI-MS assinou um manifesto no qual defendia a coordenação do DSEI-MS no caso das demissões de profissionais indígenas. Uma leitura atenta ao manifesto do presidente do CONDISI-MS evidencia o arremedo dos argumentos do gestor, de tal forma que o manifesto gerou ainda mais indignação a outros conselheiros. No dia 07 de janeiro de 2021, em reunião virtual sem a presença do presidente, diversos conselheiros distritais elencaram queixas e decidiram encaminhar ofício ao secretário nacional da SESAI, informando a destituição do presidente e do vice. Entre as queixas, registraram que ambos haviam assinado documentos sem apreciação do plenário, inclusive, ratificando demissões de indígenas para dar respaldo político aos atos do coordenador. No dia 14 de janeiro, foi publicado um informativo do CONDISI-MS, emitido por uma comissão provisória, destinado aos demais conselheiros e lideranças indígenas do estado, afirmando que a interlocução entre CONDISI-MS e DSEI-MS se encontrava prejudicada, "culminando na não realização de assembleias"; que o presidente havia participado de evento em Brasília para tratar da Portaria No. $3.021^{8}$ sem reportar o que fora discutido e que ele "fora sozinho e voltara calado"; que o presidente e vice "decidiam sozinhos" e que intencionavam "adotar 'um outro CONDISI'", "inclusive escolhiam com quem trabalhar" tendo demitido o secretário do CONDISI sem consulta ao plenário. O informativo ainda tecia comentários sobre o Secretário da SESAl, citando ofício em que ele sugeria que o presidente e o vice "permanecessem em seus respectivos cargos". Ainda, acusavam o secretário da SESAI de "apoiar um outro 'modelo de CONDISI' sem a participação dos conselheiros, apoiado apenas pelo presidente e vice". Esse informativo afirmava que presidente, vice, coordenador do DSEI-MS e Secretário da SESAI pretendiam:

[...] usurpar as funções do controle social, usavam os instrumentos e aparatos da máquina pública para estabelecer esse 'modelo de CONDISI' subalterno ao DSEI de modo que Leis, Resoluções, Estatutos,

\footnotetext{
${ }^{8}$ Trata-se da Portaria do Ministério da Saúde No. 3.021 de 04 de novembro de 2020 que reestrutura os órgãos colegiados do controle social na saúde indígena. A portaria é polêmica uma vez que, na prática, exclui o movimento indígena e organizações de apoio de participarem dos conselhos. 
Regimentos, Portarias, Decretos, nada mais vale, eles querem ser a Lei. (INFORMATIVO CONDISI-MS, Campo Grande, 14 de janeiro de 2021, divulgado em aplicativos de mensagens)

Nesse ponto, cabe fazer comentário que extrapola a gestão da saúde indígena, evocando o modo de operação análogo àquele dos anos de ditadura militar, em que a repressão se disseminava, inclusive, pela aplicação distorcida do aparato legal em prejuízo aos opositores.

Talvez o aspecto mais significativo da gestão ineficiente da saúde indígena durante a pandemia deva-se à militarização da saúde imposta pelo governo federal. O DSEI-MS vinha de uma coordenação ocupada por um indígena Terena até 2019. Aquele coordenador indígena havia promovido a participação social no CONDISI-MS, realizado cursos para capacitação de conselheiros e reuniões regulares com efetiva participação indígena. De fato, observou-se que o CONDISI-MS teve um papel atuante durante 2018 e 2019, inclusive, sendo consultado para deliberação de assuntos importantes. Com o início do governo Bolsonaro, o coordenador indígena fora demitido e em seu lugar foi empossado um historiador sem conhecimento da realidade local. Este coordenador ficou pouco tempo no cargo, pois era alinhado ao então ministro da saúde. Ele deixou a coordenação vaga logo nos primeiros meses da pandemia após a queda do ministro. O DSEI-MS passou a ter coordenação interina por alguns meses ocupada por servidor de carreira, que teve atuação restrita a procedimentos operacionais. Ele não tinha legitimidade política para decisões mais importantes que permaneceram suspensas. Seis meses depois do início da pandemia um militar fora indicado para a coordenação do DSEI-MS.

A manipulação alegórica da guerra foi levada às últimas consequências pelo governo no "combate" à pandemia e isso contribuiu para justificar a ocupação de cargos de gestão por militares sem qualquer conhecimento prático prévio de saúde pública, como foi o caso da coordenação do DSEI-MS. O coordenador da gestão militarizada do Ministério da Saúde não tinha qualquer experiência de atuação no Subsistema de Atenção à Saúde Indígena (Sasi-SUS), nem conhecimento sobre a realidade indígena no estado de MS. Isso repetia o caso anterior, porém a especificidade deste foi a alegação de uma suposta competência para a gestão administrativa. O coordenador militar trouxe consigo, contudo, um estilo de liderança incompatível com o cargo. Ele implantou uma gestão desastrosa que levou a conflitos abertos e falta de diálogo com lideranças indígenas. O coordenador implantou um clima de temor inclusive entre funcionários não indígenas do DSEI-MS, sendo que alguns preferiram deixar os postos de trabalho a submeterem-se às condições de trabalho exigidas pelo novo coordenador.

Conflitos abertos e falta de diálogo geraram prejuízos à gestão, como já apontado. Veron e Guimarães (2021) afirmam que o governo federal não foi apenas omisso na implantação de políticas públicas para enfrentar a COVID-19 nos territórios indígenas em MS, mas efetivamente 
Espaço Ameríndio

operacionalizou uma política anti-indígena. De fato, várias denúncias de "perseguição" emergiram: "Os servidores da SESAI em Mato Grosso do Sul que trabalham pela saúde indígena estão sendo perseguidos e ameaçados." (Nota de Repúdio da Aty Gasu, 06/06/2021, que circulou nos aplicativos de mensagens).

\section{Protagonismo e protestos}

As ameaças aos direitos indígenas não são fatos isolados no contexto do MS, mas se relacionam às políticas de governo claramente anti-indígenas. Tais políticas de governo têm acentuado ameaças aos direitos indígenas em âmbito nacional, a exemplo da PL 490/2007, que voltou à pauta e foi aprovada na Comissão de Constituição e Justiça e de Cidadania (CCJC) da Câmara, em plena pandemia, no dia 23 de junho de 2021. Diversos protestos indígenas ocorreram pelo país enquanto redigíamos este texto. Nesse contexto mais amplo, circulam discursos e propostas como a que considera que o país abandone a Convenção 169 da OIT, a exemplo do projeto de decreto legislativo (PDL no 177/2021). Em 2019, inclusive, um grupo de trabalho coordenado pela própria Casa Civil da Presidência chegou a propor rever parecer jurídico para subtrair a necessidade de consulta prévia aos povos indígenas ${ }^{9}$. Somam-se a isso, diversas denúncias, como as de omissão nos casos de garimpo ilegal e de roubo de madeira em terras indígenas, temas que vêm sendo amplamente noticiados ${ }^{10}$. Pautas indígenas importantes permanecem sem a atenção do governo, como as que demandam reconhecimento de territórios e as que demandam serviços de saúde adequados. A política anti-indígena tornou-se visível como marca de um governo trazendo graves consequências para a sobrevivência e reprodução biossocial dos povos indígenas.

Os protestos pela saúde indígena no MS ganharam intensidade em janeiro de 2021, quando conselheiros, lideranças e representantes das organizações indígenas passaram a exigir a exoneração do coordenador do DSEI-MS. Em 28 de janeiro de 2021, os indígenas ocuparam o pátio da sede do DSEI-MS carregando faixas e cartazes. Houve divulgação na mídia local e o prédio do DSEI-MS permaneceu fechado. No dia 29, o secretário da SESAI, que estava em visita ao estado do MS, participou de reunião para negociar a desocupação do pátio do DSEI-MS. Ficou acordado que o secretário afastaria o coordenador por um período de 15 dias para apurar as denúncias. Toda conversa entre as lideranças indígenas e o secretário da SESAl foi filmada" e acompanhada por representante do MPF. Os

\footnotetext{
9 A proposta foi notícia nas redes sociais, veja, por exemplo: http://www.ihu.unisinos.br/78noticias/593183-grupo-do-governo-articula-revisao-de-consulta-a-indios-sobre-grandes-obras

${ }^{10}$ Veja, por exemplo, o texto de Glenn H. Shepard (2021) “A wildcat doesn’t change its spots: Gold mining on Indigenous lands in Bolsonaro's Brazil”, disponível em: https:/ethnoground.blogspot.com/2021/06/awildcat-doesnt-change-its-spots-

gold.html?utm source $=$ feedburner\&utm medium $=$ email\&utm campaign $=$ Feed $\% 3 \mathrm{~A}+$ NotesFromTheEth noground $+\% 28$ Notes + from + the + Ethnoground $\% 29$

${ }^{11}$ A filmagem foi compartilhada pela internet pelo Comité de Solidariedade entre os povos, de Portugal. Disponível em https://www.facebook.com/csppt/videos/262315578577069/ 
indígenas cederam e aceitaram a promessa do secretário da SESAI. Contudo, poucos dias depois, ficou evidente que o secretário da SESAI não cumpriria a palavra. Isso causou temor e mais indignação, que contribuíram para piorar o desgaste do coordenador perante lideranças indígenas. Novas assembleias foram realizadas, em 12 e 22 de fevereiro de 2021, para exigir, mais uma vez, a exoneração do coordenador $^{12}$. Também exigiram que a SESAI explicasse as demissões ocorridas. Apesar dos protestos, a SESAI ignorou os pedidos e manteve coordenador no cargo. A SESAI defendeu o coordenador ${ }^{13}$.

Em 23 de abril, a demissão de um médico não indígena que também era conselheiro distrital de saúde indígena teve aparência de arbitrariedade e causou surpresa e revolta. O médico era reconhecido pelo trabalho de duas décadas junto aos Guarani e Kaiowá no polo base de Dourados. Ele exercia também influência muito importante no CONDISI-MS, sendo respeitado pelos demais conselheiros por defender as causas indígenas. Em entrevista a um jornal local, o médico protestou, afirmando sobre a demissão: "É uma forma de calar os profissionais. Na busca por esconder a real situação vale tudo, até mesmo assediar médicos, enfermeiros e demais profissionais que tentam salvar vidas diariamente." 14.

Entre 03 e 11 de maio de 2021, os indígenas ocuparam a sede do polo base de Dourados exigindo a exoneração da chefe do polo. Eles a acusaram de ter influenciado as demissões e de realizar assedio moral contra trabalhadores indígenas. Foram dias de mobilização e protestos feitos pelos indígenas por meio de faixas, ocupação do polo base e publicação de notas nas redes sociais. Desde a segunda-feira do dia 03 de maio, circulavam notícias nos grupos de WhatsApp imagens, áudios e textos sobre o protesto em Dourados. Vários indígenas manifestavam-se inconformados com a gestão do polo base, do DSEI-MS e da SESAI. Eles acusavam os gestores de assédio moral e denunciavam as precárias condições de trabalho. Em um vídeo divulgado nas redes sociais e aplicativos de mensagens, uma das lideranças indígenas protestava em meio a faixas e cartazes que diziam "basta de perseguição", " ditadura aqui não", "fora Fulana [chefe do polo]", "assédio moral basta":

Estamos aqui no PB de Dourados hoje, com a presença de algumas lideranças, cobrando respeito à saúde indígena. Pedindo Fora Fulana [chefe do polo base] que é gestora aqui do polo, por conta das perseguições que eles estão fazendo com os profissionais que representam a luta indígena. O movimento nosso é com os usuários e lideranças aqui da aldeia mesmo. Estamos cansados de ser

\footnotetext{
12 Veja nota informativa sobre os dois encontros realizados, e publicada em 12 de março de 2021 em: $<$ https://www.facebook.com/indigenams/photos/pcb.1671608366356263/1671608279689605>, $<$ https://www.facebook.com/indigenams/photos/pcb.1671608366356263/1671608329689600>.

${ }^{13}$ Conforme vídeo enviado aos indígenas de MS em que o secretário da SESAI expõe a decisão pela continuidade do coordenador, disponível em: https://www.youtube.com/watch? $\mathrm{v}=\mathrm{H} 643 Z \mathrm{Z}$ Q3ByQ\&t=10s ${ }^{14}$ Matéria disponível em: https://www.progresso.com.br/cotidiano/apos-20-anos-na-saude-indigena-zelike-exonerado-sem-justificativa/382302/
} 
desrespeitados e a nossa saúde tá precária enquanto nossos gestores, lá em cima, dizem que tá tudo bem. Chega de mentira, chega de assédio moral. Nós queremos respeito. Isso que nós estamos cobrando. Então, fora Fulana, fora [Coordenador] e fora [secretário da SESAI]. (LIDERANÇA INDÍGENA, em vídeo compartilhado em grupo de WhatsApp, 03/05/2021)

No caso do MS, os protestos indígenas emergiram como recurso de luta contra as demissões, acusações de autoritarismo e falta de diálogo com a SESAI e o DSEI-MS. Etnografias sobre protestos indígenas afirmam que são uma forma importante de comunicação interétnica pela qual se busca ganhar visibilidade para se fazer ouvir na luta por direitos (HANNA et al., 2016).

Os indígenas tiveram sucesso em retirar a chefe do polo base Dourados do cargo. Em 27 de maio de 2021, o coordenador do DSEI-MS também foi exonerado. Entretanto, as demissões aparentemente arbitrárias de profissionais indígenas e não indígenas não foram ainda revistas. Na sequencia dos eventos, a SESAl ainda impôs advertência formal a vários profissionais do polo base de Dourados que participaram direta ou indiretamente do protesto. Segundo lideranças indígenas, as advertências, na forma de sanção disciplinar, seriam um tipo de retaliação contra os profissionais que apoiaram o protesto. Esses fatos indicariam que a lógica da falta de diálogo e retaliações permanece, por enquanto.

\section{Considerações finais: diálogo e urgência}

A crise sanitária trazida pela pandemia de COVID-19 deu visibilidade a problemas que permanecem na saúde indígena há décadas: violências e conflitos por terras; desnutrição e insegurança alimentar; falta de saneamento básico, inclusive de água potável; taxas elevadas de doenças crônicas e infecciosas superiores às da população não indígena; carência de profissionais de saúde na atenção primária; precária infraestrutura em postos de saúde nas aldeias; péssimas condições de trabalho para profissionais de saúde; gestão ineficiente da atenção primária; e limitada participação social indígena no planejamento e avaliação dos serviços prestados, entre outros.

Do ponto de vista dos conselheiros distritais, das lideranças locais e de representantes das organizações indígenas, não houve espaço para o diálogo com os gestores da atenção primária neste período de pandemia. Os obstáculos à participação indígena afetaram a qualidade dos serviços com impacto direto sobre condições de vida dos povos indígenas no MS. A falta de participação social na gestão durante a pandemia causou prejuízos à atenção primária. A participação social indígena é um dos pilares da PNASPI e o exercício do controle social tem potencial para mitigar os efeitos das iniquidades em saúde. As assimetrias de poder no contexto da saúde indígena no Brasil replicam relações de hegemonia e subalternidade entre os distintos atores sociais 
e, assim, tendem a perpetuar as condições de iniquidade em saúde (LANGDON, 2004; MENÉNDEZ, 2009; BRIGGS, 2017; FOLLÉR, 2004). É necessário que existam incentivos à participação social por parte dos gestores públicos e que esforços sejam realizados no sentido de minimizar as assimetrias de poder que caracterizam as relações interétnicas entre povos indígenas e sociedade nacional.

As relações de hegemonia e subalternidade evidenciam-se através da ausência de participação indígena em "espaços de gestão pública e de tomadas de decisões" onde persiste "[...] perspectiva marcadamente silenciadora e colonial [...]" (BANIWA; TUXÁ; TERENA, 2020, p. 7). Essa perspectiva precisa ser combatida para que se alcancem melhores condições de vida para os povos indígenas, bem como para melhorar a própria eficiência dos serviços de saúde prestados pelo Estado.

O modelo monológico de comunicação que se impôs ao campo da saúde indígena produz um fluxo comunicativo unidirecional com desconhecimento sistemático ou incompleto das realidades locais, pois a perspectiva indígena é ignorada ou negada. Tal modelo monológico se pauta sobre um princípio de hierarquia entre pessoas e saberes que se caracteriza pela verticalidade "de cima para baixo" (MARTíNEZ-HERNÁEZ, 2010, p. 404) $)^{15}$.

A falta de diálogo e os conflitos entre indígenas e a coordenação do DSEI-MS caracterizam o monólogo autoritário que se implantou como política de gestão local. Não bastasse a ineficiência de tal modelo de comunicação e gestão, o monólogo em um contexto interétnico de racismo e violência estrutural, adquire um significado mais grave. Para se compreender tal significado, observa-se que os povos indígenas no MS vivem uma luta cotidiana pelo direito ao território. Em tal contexto de violência, calar a voz é expressão da injustiça social. O silenciamento é constituinte do fluxo comunicativo unidirecional assimétrico.

Para Martinéz-Hernáez (2010), a atenção à saúde deve estar pautada por um modelo dialógico de comunicação. Para o autor, a comunicação monológica e unidirecional - ou seja, autoritária - dissocia o processo de saúde/doença/atenção/prevenção dos contextos socioculturais, econômicos e políticos em que ocorre, ou seja, situa-se como processo "alheio às populações, às suas histórias e às suas estruturas sociais". A falta de diálogo na gestão, evidentemente, é um desrespeito e uma violência aos povos indígenas, não obstante seja causa de ineficiência na gestão da atenção à saúde indígena. Na pandemia, essa falta de diálogo operacionalizou uma política de governo que comprometeu as ações de enfrentamento à COVID-19. Parafraseando

\footnotetext{
${ }^{15}$ Do tipo "simples assim. um manda, o outro obedece", conforme fala do militar ex-ministro da saúde ao Presidente da República, quando este desautorizou a compra de vacinas, conforme amplamente divulgado pela mídia em 22/10/2020. https:/g1.globo.com/politica/noticia/2020/10/22/e-simples-assim-um-mandae-o-outro-obedece-diz-pazuello-ao-lado-de-bolsonaro.ghtml
} 
Espaço Ameríndio

Jurema Werneck, ouvir e dialogar "era uma obrigação e não uma questão de opinião"16.

Para Briggs (2017), as assimetrias de poder são mantidas através da estrutura hierárquica das equipes de saúde e entre as diversas instituições e o governo gerando graves injustiças em saúde. O autor lembra que os processos de saúde/doença/atenção são processos comunicacionais e que é necessário que exista justiça em comunicação em saúde para gerar ações com efetividade no contexto interétnico. Como afirma Langdon (1994), nos processos de saúde/doença/atenção há constante interação e negociação entre atores sociais sobre como interpretar e sobre quem tem legitimidade para impor interpretações sobre os acontecimentos. Nesse sentido, superar as falhas estruturais na atenção à saúde dos povos indígenas passa pela necessidade de se garantir justiça em saúde e em comunicação. A necessidade de relações dialógicas tem sido destacada como forma de minimizar os efeitos de hierarquias na manutenção das iniquidades estruturais em saúde (BRIGGS, 2017; MARTINÉZ-HERNÁEZ, 2010; MENÉNDEZ, 2009; LANGDON, 2004).

O quadro de profundas injustiças sociais e de condições de vulnerabilidade foi decisivo para a gravidade da pandemia de COVID-19 entre os povos indígenas no Brasil e, em especial, no MS. Semelhante a outros contextos em várias partes do globo, as iniquidades observadas possuem um claro recorte étnico-racial e de classe que se relacionam com condições sociais vivenciadas por coletividades em situação de vulnerabilidade (MENENDÉZ, 2020; HALLAL et al., 2020; FELLOWS, et al., 2021; SIMIONATTO et al., 2020; RANZANI et al., 2021; PONTES et al., 2021; SINGER e RYLKO-BAUER, 2021).

A pandemia de COVID-19 entre os povos indígenas no MS deixa lições que precisam ser observadas. Uma delas é de que a urgência não deve ser a do "rápido retorno ao mundo como o conhecíamos" (SINGER e RYLKO-BAUER, 2021,p.21), mas, sim, a de conquistar um futuro em que problemas de saúde e injustiças sociais sejam enfrentados concomitantemente. A violência estrutural agrava o cenário sindêmico (SINGER e RYLKO-BAUER, 2021). Fatores como racismo, opressão e discriminação tenderam a interagir de forma sinérgica com a pandemia da COVID-19, agravando-a. Neste cenário, a distinção, historicamente construída, entre políticas de saúde e políticas sociais deve ser reconsiderada (KLEINMAN, 2010 apud SINGER e RYLKO-BAUER, 2021). Problemas de saúde são, antes de tudo, problemas sociais e para lidar com ambos é necessário estabelecer políticas que fortaleçam a participação social, os modelos de gestão dialógicos e o combate à violência e racismo estruturais.

16 https:/g1.globo.com/politica/cpi-da-covid/noticia/2021/06/24/era-obrigacao-nao-era-questao-deopiniao-diz-pesquisadora-a-cpi-sobre-falta-de-estrategia-nacional-contra-acovid.ghtml?utm_source $=$ twitter\&utm_medium $=$ social\&utm_campaign $=\mathrm{g} 1$ 
Espaço Ameríndio

\section{Referências bibliográficas}

ALBERT, B. Yanomami: os mortos "desaparecidos" da pandemia. In: MACHADO, Ana Maria et al. (org). Xawara: rastros da Covid-19 na Terra Indígena Yanomami e a omissão do Estado. São Paulo: Instituto Socioambiental, p 25-28. 2020.

ATHIAS, R. Índios, antropólogos e gestores de saúde no âmbito dos Distritos Sanitários Especiais Indígenas. LANGDON E.J.; GARNELO L. (Orgs). Saúde dos povos indígenas: reflexões sobre antropologia participativa, RJ: Ed. Contracapa; 2004. p. 217 232.

ATHIAS, R. and MACHADO, M. A saúde indígena no processo de implantação dos Distritos Sanitários: temas críticos e propostas para um diálogo interdisciplinar. Cad. Saúde Pública vol.17, n.2, pp.425-431, Mar. 2001. Disponível em: http://dx.doi.org/10.1590/S0102-311X2001000200017.

BANIWA, Braulina; TUXÁ, Felipe Cruz; TERENA, Luiz Eloy. Apresentação: A pandemia de Covid-19 na vida dos povos indígenas. Vukápanavo: Revista Terena, $\mathrm{n}^{\circ} 3$, p. 7-11, out./nov. 2020.

BASTA, Paulo Cesar; MARQUES, Marli; OLIVEIRA, Roselene Lopes de; Cunha, Eunice Atsuko Totumi; RESENDES, Ana Paula da Costa; SOUZA-SANTOS, Reinaldo. Desigualdades sociais e tuberculose: análise segundo raça/cor, Mato Grosso do Sul. Revista de saúde pública, v. 47, p. 854-864, 2013.

BRAND, Antonio. Os complexos caminhos da luta pela terra entre os Kaiowá e Guarani no MS. Tellus, p. 137-150, 2004.

BRASIL.Ministério da Saúde. Secretaria Especial de Saúde Indígena. Distrito Sanitário Especial Indígena de Mato Grosso do Sul. Plano Distrital de Saúde Indígena 2020-2023DSEI Mato Grosso Do Sul. Campo Grande-MS, 2020.

BRASIL. Ministério da Saúde. Política Nacional de Atenção à Saúde dos Povos Indígenas. 2 ed. Brasília: Funasa, Ministério da Saúde, 2002.

BRASIL. Decreto $\mathrm{n}^{\circ} 10.088$, de 5 de novembro de 2019. Consolida atos normativos editados pelo Poder Executivo Federal que dispõem sobre a promulgação de convenções e recomendações da Organização Internacional do Trabalho - OIT ratificadas pela República Federativa do Brasil. Diário Oficial da União. Brasília, DF, 5 de novembro de 2019. Disponível em: http://www.planalto.gov.br/ccivil 03/ Ato20192022/2019/Decreto/D10088.htm\#art5.

BRIGGS, Charles L. Descubriendo una falla trágica en las políticas revolucionarias de salud: Desde las inequidades en salud y comunicación a la justicia comunicativa en salud. Salud Colectiva, v. 13, p. 411-427, 2017.

CONSELHO INDIGENISTA MISSIONÁRIO. Relatório Violência contra os Povos Indígenas no Brasil-Dados de 2019. Brasília: Cimi, 2020. Disponível em: https://cimi.org.br/wp-content/uploads/2020/10/relatorio-violencia-contra-os-povosindigenas-brasil-2019-cimi.pdf 
CODEÇO, Cláudia T. et al. Risco de espalhamento da Covid-19 em populações indígenas: considerações preliminares sobre vulnerabilidade geográfica e sociodemográfica. Rio de Janeiro: Fiocruz/ENSP/PROCC; FGV, 36 p. $4^{\circ}$. Relatório, 18 abril 2020. Disponível em: https://www.arca.fiocruz.br/bitstream/icict/40980/2/EspalhamentoCovidIndigenasRelat \%c3\%b3riosT\%c3\%a9cnicos.pdf

COIMBRA JR, Carlos Everaldo Alvares. Saúde e povos indígenas no Brasil: reflexões a partir do I Inquérito Nacional de Saúde e Nutrição Indígena. Cadernos de Saúde Pública, v. 30, p. 855-859, 2014. Disponível em: https://www.scielosp.org/article/csp/2014.v30n4/855-859/pt/

CUPERTINO, Graziela Almeida et al. COVID-19 and Brazilian indigenous populations. The American journal of tropical medicine and hygiene, v. 103, n. 2, p. 609-612, 2020.

DIAS-SCOPEL, Raquel; SCOPEL, Daniel; DIEHL, Eliana Elisabeth. Participação Indígena e Obstáculos ao Enfrentamento da Pandemia de Covid-19 no Mato Grosso do Sul. In: MATTA, G.C; REGO, S.; SOUTO, E.P; SEGATA, J. (eds.). Os impactos sociais da Covid-19 no Brasil: populações vulnerabilizadas e respostas à pandemia [online]. Rio de Janeiro: Observatório Covid 19; Editora FIOCRUZ, p. 137-148. 2021.

DIEHL, E.E e LANGDON, J. Indigenous participation in primary care services in Brazil - Autonomy or bureaucratization? Regions and Cohesion, v. 8; p. 54-76, 2018.

FÁVARO, T.; RIBAS, D. L B.; ZORZATTO, J. R.; SEGALL-CORRÊA, A. M.; PANIGASSI, G. Segurança alimentar em famílias indígenas terena, Mato Grosso do Sul, Brasil. Cadernos de Saúde Pública, 23(4), p. 785-793, 2007.

FELLOWS, Martha et al. Under-reporting of COVID-19 cases among Indigenous Peoples in Brazil: a new expression of old inequalities. Frontiers in Psychiatry, v. 12, p. $352,2021$.

FERREIRA, M. E. V.; MATSUO, T.; SOUZA, R. K. T. D. Aspectos demográficos e mortalidade de populações indígenas do Estado do Mato Grosso do Sul, Brasil. Cadernos de Saúde Pública, 27 (12), p. 2327-2339, 2011.

FOLLÉR, Maj-Lis. Intermedicalidade: a zona de contato criada por povos indígenas e profissionais de saúde. LANGDON E.J.; GARNELO L. (Orgs). Saúde dos povos indígenas: reflexões sobre antropologia participativa, p. 129-147, 2004.

GARNELO, Luiza. Poder, hierarquia e reciprocidade: saúde e harmonia entre os Baniwa do Alto Rio Negro. Rio de Janeiro:Editora Fiocruz, 2003.

HALLAL, Pedro C. et al. SARS-CoV-2 antibody prevalence in Brazil: results from two successive nationwide serological household surveys. The Lancet Global Health, v. 8, n. 11, p. e1390-e1398, 2020.

HANNA, Philippe; LANGDON, Esther Jean; VANCLAY, Frank. Indigenous rights, performativity and protest. Land Use Policy, v. 50, p. 490-506, 2016. 
Espaço Ameríndio

LANGDON, Esther Jean. Uma avaliação crítica da atenção diferenciada e a colaboração entre antropologia e profissionais de saúde. LANGDON E.J.; GARNELO L. (Orgs). Saúde dos povos indígenas: reflexões sobre antropologia participativa. Rio de Janeiro: Contra Capa, p. 29-45, 2004.

LANGDON, Esther Jean. A negociação do oculto: xamanismo, família e medicina entre os Siona no contexto pluri-étnico. 1994. Trabalho apresentado para concurso público de professor titular. Florianópolis: Universidade Federal de Santa Catarina, 1994.

LANGDON, Esther Jean; DIEHL, Eliana E. Participação e autonomia nos espaços interculturais de saúde indígena: reflexões a partir do sul do Brasil. Saúde e sociedade, v. 16, p. 19-36, 2007.

MARTÍNEZ-HERNÁEZ, Angel. Dialógica, etnografia e educação em saúde. Revista de Saúde Pública, v. 44, p. 399-405, 2010.

MENDES, Matheus Ferreira et al. COVID-19 pandemic evolution in the Brazilian Indigenous population. Journal of Racial and Ethnic Health Disparities, p. 1-17, 2021.

MENÉNDEZ, EL. Sujeitos, saberes e estruturas: uma introdução ao enfoque relacional no estudo da saúde coletiva. São Paulo: Editora Hucitec; 2009.

MENÉNDEZ, Eduardo L. Consecuencias, visibilizaciones y negaciones de una pandemia: los procesos de autoatención. Salud Colectiva, v. 16, p. 1-23, 2020.

PÍCOLI, Renata Palópoli; CAZOLA, Luiza Helena de Oliveira; LEMOS, Everton Ferreira. Mortalidade materna segundo raça/cor, em Mato Grosso do Sul, Brasil, de 2010 a 2015. Revista Brasileira de Saúde Materno Infantil, v. 17, p. 729-737, 2017.

PONTES, A.L.M; CARDOSO, A.M; BASTOS, L.S; SANTOS, R.V. Pandemia de Covid19 e os povos indígenas no Brasil: cenários sociopolíticos e epidemiológicos. In: MATTA, G.C; REGO, S.; SOUTO, E.P.; SEGATA, J. (eds.). Os impactos sociais da Covid-19 no Brasil: populações vulnerabilizadas e respostas à pandemia [online]. Rio de Janeiro: Observatório Covid 19; Editora FIOCRUZ, p. 123- 136, 2021.

RANZANI, Otavio T. et al. Characterisation of the first 250000 hospital admissions for COVID-19 in Brazil: a retrospective analysis of nationwide data. The Lancet Respiratory Medicine, v. 9, n. 4, p. 407-418, 2021.

RIBAS, Dulce Lopes Barboza; PHILIPPI, Sônia Tucunduva. Aspectos alimentares e nutricionais de mães e crianças indígenas Teréna, Mato Grosso do Sul. COIMBRA JR. C. E. A., SANTOS R. V., ESCOBAR A. L., (Orgs). Epidemiologia e saúde dos povos indígenas no Brasil. Rio de Janeiro: Editora Fiocruz/ABRASCO, p. 73-88, 2003.

SCOPEL, Daniel; DIAS-SCOPEL, Raquel Paiva; LANGDON, Esther Jean. Intermedicalidade e protagonismo: a atuação dos agentes indígenas de saúde Munduruku da Terra Indígena Kwatá-Laranjal, Amazonas, Brasil. Cadernos de Saúde Pública, v. 31, p. 2559-2568, 2015. 
Espaço Ameríndio

SHEPARD, GH (2021) “A wildcat doesn’t change its spots: Gold mining on Indigenous lands in Bolsonaro's Brazil", disponível em: https://ethnoground.blogspot.com/2021/06/a-wildcat-doesnt-change-its-spotsgold.html?utm_source $=$ feedburner\&utm medium $=$ email\&utm_campaign $=$ Feed $\% 3 \mathrm{~A}+\mathrm{N}$ otesFromTheEthnoground $+\% 28$ Notes + from + the + Ethnoground $\% 29$

SINGER, Merrill; RYLKO-BAUER, Barbara. The Syndemics and structural violence of the COVID pandemic: anthropological insights on a crisis. Open Anthropological Research, v. 1, n. 1, p. 7-32, 2021.

SIMIONATTO, Simone; BARBOSA, Marcelo; MARCHIORO, Silvana Beutinger. COVID-19 in Brazilian indigenous people: a new threat to old problems. Revista da Sociedade Brasileira de Medicina Tropical, v. 53, 2020.

STF. Decisão - Medida Cautelar Na Arguição De Descumprimento De Preceito Fundamental 709 Distrito Federal. Relator Ministro Roberto Barroso.16/03/2021. Disponível Em: Http:/Www.Stf.Jus.Br/Arquivo/Cms/Noticianoticiastf/Anexo/Adpf709homologparcial. Pdf Acesso Em:11/07/2021.

TEIXEIRA, Carla Costa. Participação social na saúde indígena: a aposta contra a assimetria no Brasil?. Amazônica-Revista de Antropologia, v. 9, n. 2, p. 716-733, 2018.

URQUIZA, Antonio Hilario Aguilera; PRADO, José Henrique. O impacto do processo de territorialização dos Kaiowá e Guarani no sul de Mato Grosso do Sul. Tellus, p. 49$71,2015$.

VERON, Valdelice; GUIMARÃES, Sílvia. Sobre máscaras, fumaça e fogo doméstico: experiências das mulheres Kaiowá na pandemia da Covid-19. Vukápanavo: Revista Terena - MS - Brasil, nº 3, p. 115-127, out./nov. 2020. 